\title{
Prognostic significance of dysadherin expression in epithelioid sarcoma and its diagnostic utility in distinguishing epithelioid sarcoma from malignant rhabdoid tumor
}

Teiyu Izumi ${ }^{1}$, Yoshinao Oda ${ }^{1}$, Tadashi Hasegawa ${ }^{2}$, Yukihiro Nakanishi ${ }^{3}$, Hiroshi Iwasaki ${ }^{4}$, Hiroshi Sonobe $^{5}$, Hiroaki Goto ${ }^{6}$, Hidenari Kusakabe ${ }^{7}$, Tomonari Takahira ${ }^{1,8}$, Chikashi Kobayashi $^{1}$, Ken-ichi Kawaguchi ${ }^{1,8}$, Tsuyoshi Saito ${ }^{1,8}$, Hidetaka Yamamoto ${ }^{1}$, Sadafumi Tamiya ${ }^{1}$, Yukihide Iwamoto ${ }^{8}$ and Masazumi Tsuneyoshi ${ }^{1}$

${ }^{1}$ Department of Anatomic Pathology, Pathological Sciences, Graduate School of Medical Sciences, Kyushu University, Fukuoka, Japan; ${ }^{2}$ Department of Clinical Pathology, Sapporo Medical University School of Medicine, Sapporo, Japan; ${ }^{3}$ Pathology Division, National Cancer Center Research Institute, Tokyo, Japan; ${ }^{4}$ Department of Pathology, School of Medicine, Fukuoka University, Fukuoka, Japan; ${ }^{5}$ Department of Pathology, Fukuyama Medical Center, Hiroshima, Japan; ${ }^{6}$ Department of Pediatrics, Yokohama City University School of Medicine, Yokohama, Japan; ${ }^{7}$ Department of Dermatology, Osaka Medical College, Osaka, Japan and ${ }^{8}$ Department of Orthopaedic Surgery, Graduate School of Medical Sciences, Kyushu University, Fukuoka, Japan

Dysadherin is a cancer-associated cell membrane glycoprotein, which downregulates E-cadherin and promotes metastasis. We studied the clinicopathological features in 72 cases of epithelioid sarcoma and in six cases of malignant rhabdoid tumor, and also assessed the immunohistochemical expression of dysadherin, E-cadherin and MIB-1 in epithelioid sarcoma and malignant rhabdoid tumor cases. In addition, we compared dysadherin mRNA expression between epithelioid sarcoma and malignant rhabdoid tumor cell lines, using RT-PCR and realtime quantitative RT-PCR analysis. Immunohistochemical dysadherin expression was more frequently observed in proximal-type epithelioid sarcoma $(71 \%)$ in comparison with distal-type epithelioid sarcoma $(36 \%)(P=0.037)$. Furthermore, seven proximal-type epithelioid sarcoma cases mimicking malignant rhabdoid tumor (histologically classified as the large cell type, accompanied by frequent rhabdoid cells and located in deep soft tissue) were all positive for dysadherin (100\%), whereas dysadherin expression was not detected at all in any of the true six malignant rhabdoid tumors $(0 \%)$. Cell lines established from proximal-type epithelioid sarcoma revealed significantly higher levels of dysadherin mRNA expression, compared with the levels seen in malignant rhabdoid tumor cell lines by real-time quantitative RT-PCR $(P=\mathbf{0 . 0 4 3 3})$. Epithelioid sarcoma patients with dysadherin expression survived for a significantly shorter time than those without dysadherin expression $(P=0.001)$. In multivariate analysis, dysadherin immunopositivity $(P=\mathbf{0 . 0 0 0 4})$ was one of the two independent adverse prognostic factors. We conclude that dysadherin expression in epithelioid sarcoma is a significant poor prognostic factor and that it is a powerful diagnostic marker for distinguishing epithelioid sarcoma, including the proximal-type epithelioid sarcoma, from malignant rhabdoid tumor. In epithelioid sarcoma, especially in proximal-type epithelioid sarcoma, increased cell disadhesion and motility by dysadherin plays an important role to acquire aggressive biological behavior. However, in malignant rhabdoid tumor, cell growth cycle that is regulated by hSNF5/INI1 gene seems to be critical to lethal biological behavior rather than dysadherin. Modern Pathology (2006) 19, 820-831. doi:10.1038/modpathol.3800599; published online 24 March 2006

Keywords: dysadherin; epithelioid sarcoma; malignant rhabdoid tumor; prognosis; diagnosis; immunohistochemistry

Correspondence: Dr Y Oda, MD, Department of Anatomic Pathology, Pathological Sciences, Graduate School of Medical Sciences, Kyushu University, Maidashi 3-1-1, Higashi-ku, Fukuoka 812-8582, Japan.

E-mail: oda@surgpath.med.kyushu-u.ac.jp

Received 8 December 2005; revised and accepted 2 March 2006; published online 24 March 2006
Epithelioid sarcoma was initially described as a distinct clinicopathological entity by Enzinger in 1970. ${ }^{1}$ The classical distal-type epithelioid sarcoma occurs in the distal extremities, mainly in the hand and around the wrist of young adults. It is known to be slowly progressive, appearing as multiple, superficial soft-tissue tumors. Epithelioid sarcoma has 
also been reported to occur in the proximal region of the extremities and in the trunk, as proximal-type epithelioid sarcoma. ${ }^{2-4}$ Malignant rhabdoid tumor usually occurs in young children across a wide range of anatomical sites, and this tumor follows a rapidly and aggressive clinical course. Rhabdoid cells with intermediate filamentous inclusion bodies have been found in a large variety of softtissue tumors. ${ }^{5}$ In particular, one of the most difficult tumors to distinguish from malignant rhabdoid tumor is the proximal-type of epithelioid sarcoma. $^{2,3,6}$ Some authors ${ }^{7}$ have described proximal-type epithelioid sarcoma as being a variant of extra-renal malignant rhabdoid tumor, while other authors $^{2,8,9}$ have demonstrated that both tumors are distinctly different entities. Some data exist regarding the histological and immunohistochemical differences between the proximal-type of epithelioid sarcoma and malignant rhabdoid tumor, but such findings have not yet been found to be conclusive. ${ }^{10}$ In the current study, we compared epithelioid sarcoma and malignant rhabdoid tumor clinicopathologically and focused on the differences in dysadherin expression between these two types of tumor. The aim of this study was to clarify differences in biological behavior and immunohistochemical profile between the tumors.

\section{Materials and methods}

\section{Cases and Specimens}

Cases were selected from among more than 12000 cases of bone and soft-tissue tumors registered in the Department of Anatomic Pathology, Graduate School of Medical Sciences, Kyushu University, Fukuoka, Japan and in the National Cancer Center, Tokyo, Japan, between 1955 and 2004. As written informed consent was not obtained, identifying information for all cases was removed before analysis for strict privacy protection. There were 72 cases of epithelioid sarcoma, and six cases of malignant rhabdoid tumor. Subtypes of epithelioid sarcoma comprised 37 cases of distal-type and 35 cases of proximal-type. We distinguished between distal-type epithelioid sarcoma and proximal-type epithelioid sarcoma based on the anatomical site of the tumor. Histologically, distal-type epithelioid sarcoma typically shows a nodular or multinodular proliferation of mainly spindle-shaped cells admixed with epithelioid cells (conventional type) (Figure 1a and b). In contrast, proximal-type epithelioid sarcoma typically reveals a diffuse proliferation of large epithelioid carcinoma-like cells with marked cytologic atypia and frequent occurrence of rhabdoid features (large cell type) (Figure 1c and d). As described by Hasegawa, ${ }^{8}$ proximal-type epithelioid sarcoma are classified into three histologic subtypes (large cell type, conventional type and angiomatoid type). In the current study, both distaltype epithelioid sarcoma and proximal-type epithe- lioid sarcoma were classified into three histologic subtypes. Malignant rhabdoid tumor comprised three cases of renal type and three cases of extrarenal type. The tumor cells typically had abundant eosinophilic cytoplasmic inclusions, and the nuclei were eccentrically located, vesicular, and had prominent central nucleoli, frequently demonstrating a so-called rhabdoid appearance (Figure 1e and f). In all six malignant rhabdoid tumor cases, no other clear alternative line of histological differentiation could be documented. That is the histological difference between proximal-type epithelioid sarcoma and malignant rhabdoid tumor. Survival data were available for 71 cases of epithelioid sarcoma and six cases of malignant rhabdoid tumor. Follow-up ranged from 1 to 251 months (mean, 50.7 months) in epithelioid sarcoma. All six malignant rhabdoid tumor patients died of disease at between 1 and 10 months (mean, 6.3 months) after diagnosis. In order to assess the correlation between clinicopathologic factors and dysadherin expression, the anatomical site of the tumor, histologic subtype, age, sex, tumor size, tumor depth, mitotic rate, tumor necrosis, the presence of rhabdoid cells, hemorrhage and vascular permeation were analyzed. The influence of these factors on prognosis has been previously reported..$^{11}$

\section{Immunohistochemistry}

Immunohistochemical study was performed using mouse IgG monoclonal antibodies against dysadherin $^{12}$ (NCC-M53, 1:1000, National Cancer Center, Tokyo), E-cadherin (1:1000, BD Transduction Laboratories, San Jose, CA, USA) and Ki-67 (MIB-1, 1:100, Dako, Grostrup, Denmark). From among the 72 cases of epithelioid sarcoma, 46 cases were suitable for dysadherin and E-cadherin immunostaining and 52 cases were suitable for MIB-1 immunostaining, whereas in the case of malignant rhabdoid tumor, all six cases could be studied using the three kinds of antibodies. Specimens are pretreated in an autoclave for dysadherin $(20 \mathrm{~min}$, $120^{\circ} \mathrm{C}$ ) or in a microwave oven for E-cadherin and MIB-1 (20 min in both cases). Sections were incubated with the primary antibodies at $4^{\circ} \mathrm{C}$ overnight, followed by staining with a streptavidin-biotinperoxidase kit (Nichirei, Tokyo, Japan). Staining for dysadherin was localized to the cell membranes. The pattern of dysadherin immunostaining in tumors was compared with that observed in the basal cells of normal skin tissue, endothelial cells and lymphocytes. Tumors were classed as dysadherinpositive when more than $50 \%$ of the cells were stained. ${ }^{13-16}$ The MIB-1-labeling index was estimated as the percentage of Ki-67-positive cells based on a count of 1000 tumor cells within the tumor. Dysadherin and E-cadherin expression were evaluated by four of the authors (TI, YO, TH and MT) without any knowledge of the clinical features in each case. 

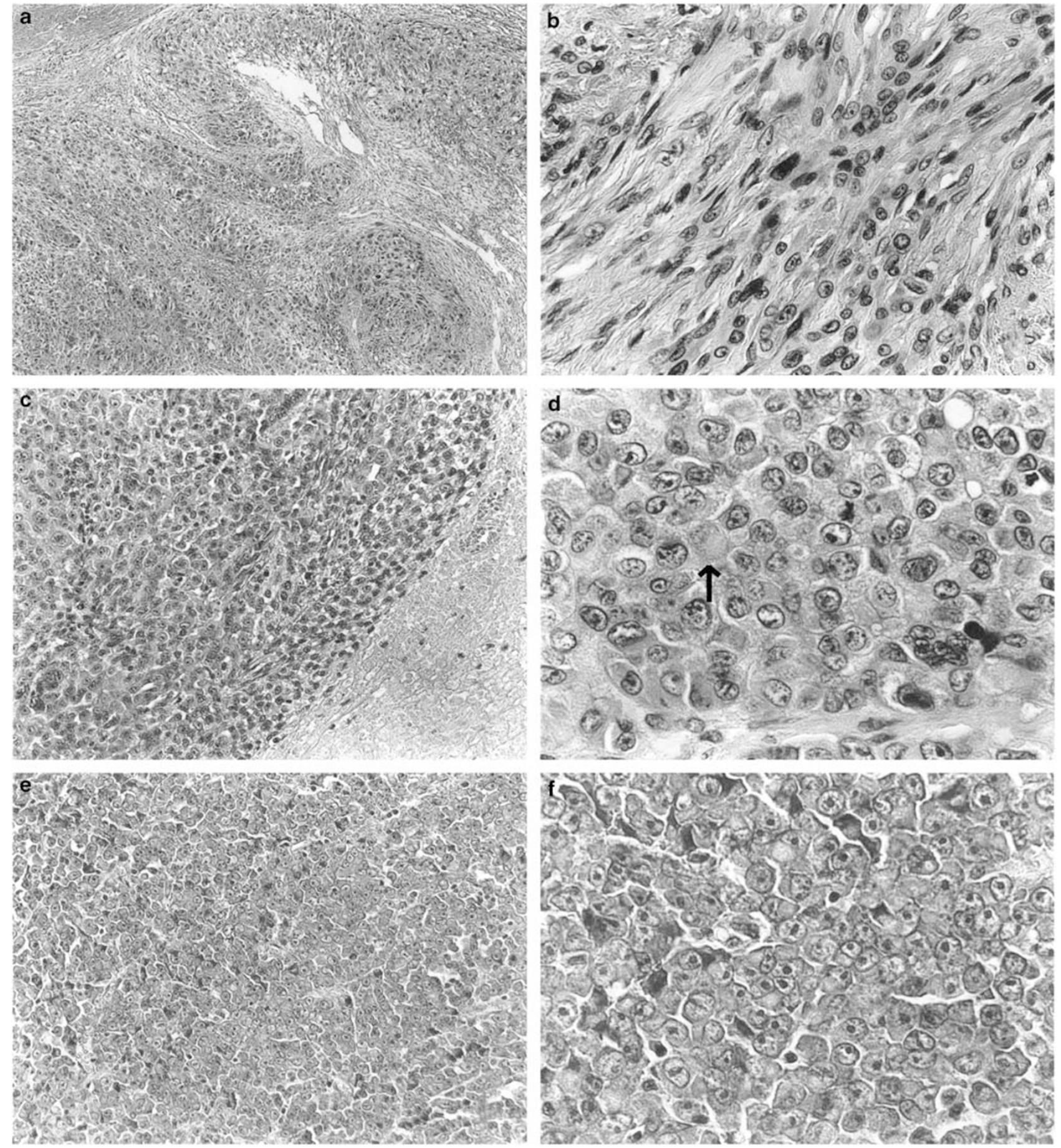

Figure 1 Distal-type epithelioid sarcoma typically shows a nodular or multinodular proliferation of mainly spindle-shaped cells admixed with epithelioid cells (conventional type) (a, b). Proximal-type epithelioid sarcoma typically reveals a diffuse proliferation of large carcinoma-like epithelioid cells with geographic tumor necrosis (c). Marked cytologic atypia and a rhabdoid cell (black arrow) are also observed (large cell type) (d). Malignant rhabdoid tumor typically has abundant eosinophilic cytoplasmic inclusions, and the nuclei are eccentrically located, vesicular, and have prominent central nucleoli, frequently showing a so-called rhabdoid appearance (e, f). No other clear alternative line of histological differentiation could be documented.

\section{Cell Culture}

Four epithelioid sarcoma cell lines (HS-ES-1M, ${ }^{17}$ YCUS-5, ${ }^{18}$ ES-OMC-MN, ${ }^{19}$ SFT8606 ${ }^{20}$ ) and four malignant rhabdoid tumor cell lines (TM87-16, ${ }^{21}$ TTC549, ${ }^{22}$ TC289, $^{23}$ STM91-01 ${ }^{24}$ ) were generously provided by the co-authors for this study. HS-ES-1M and YCUS-5 were established from proximaltype epithelioid sarcoma, while ES-OMC-MN and SFT8606 were established from distal-type epithelioid sarcoma. Human hepatoma Li-7 and PLC/PRF/ 5 cell lines were obtained from the Institute of 
Development, Aging and Cancer, Tohoku University. Cells were cultured in RPMI-1640, DMEM or DMEM/F-12 (GIBCO/BRL) supplemented with 10\% FBS (GIBCO/BRL) in a humidified atmosphere of $5 \%$ $\mathrm{CO}_{2}$ and $95 \%$ air.

\section{RT-PCR and Real-Time Quantitative RT-PCR to Detect Dysadherin mRNA}

Total RNA was prepared, using Trizol Reagent (Invitrogen Corp., Carlsbad, CA, USA) according to the manufacturer's protocol. RNA $(5 \mu \mathrm{l})$ in each sample were used for the subsequent reverse transcription. Sequences of specific pairs of primers were as follows: dysadherin (upper primer: $5^{\prime}$-AGA GCA CCA AAG CAG CTC AT-3'; lower primer: $5^{\prime}$ GGG TCT GTC TGG ACG TCT GT-3'; product size, $85 \mathrm{bp})$. The PCR products were electrophoresed in $2.0 \%$ agarose gel and visualized with ethidium bromide. cDNA from the Li-7 human hepatoma cell line was used as a positive control for dysadherin expression, and PLC/PRF/5 was used as a negative control. ${ }^{12}$

Real-time quantitative RT-PCR (TaqMan PCR) for dysadherin was performed using an ABI PRISM 7700 Sequence Detection System (Applied Biosystems, Foster City, CA, USA) and predeveloped TaqMan assay reagents of human dysadherin and $G A P D H$. The PCR reaction was carried out according to the manufacturer's protocol. ${ }^{25}$ The standard curve was constructed with serial dilutions of the cDNA samples of Li-7. All reactions of the samples were triplicated and the data were averaged from the values obtained in each reaction. To determine the mRNA levels of dysadherin, we used an mRNA expression index (EI), which is a relative mRNA expression level standardized by using the internal housekeeping gene, GAPDH. The dysadherin mRNA EI was calculated as follows (in AU): mRNA $\mathrm{EI}=$ (copy numbers of dysadherin mRNA/copy numbers of GAPDH mRNA) X 1000 AU. A high (low) level of dysadherin expression was defined as an mRNA EI above (below) the value of hepatoma Li-7 cell line.

\section{Statistical Analysis}

The survival curves were analyzed by the KaplanMeier method and the outcome of different groups of patients was compared by the log-rank test. The Cox proportional hazards regression with the stepwise procedure was used in multivariate analysis of survival data. Fisher's exact test was used to evaluate the association between two dichotomous variables. The correlations between each group and mRNA expression were determined by using the Mann-Whitney $U$ test. Probability values of $<0.05$ were considered as significant.

\section{Results}

\section{Clinical and Histological Findings}

\section{Epithelioid sarcoma}

The clinicopathological findings of 72 cases of epithelioid sarcoma are summarized in Table 1. In all, 37 patients were affected at distal sites, whereas 35 patients had a tumor at proximal sites. Histologically, 46 patients were classified as the conventional type, five as the angiomatoid type and 21 as the large cell type. Rhabdoid cells were detected to varying degrees in 42 cases (distal-type: 18/37 cases; proximal-type: $24 / 35$ cases), but were absent in 30 cases. The correlation between the tumor site in all the epithelioid sarcoma cases and histologic subtype is summarized in Table 2. The proximal-type often demonstrated the large cell type (57\%: 20/35 cases), whereas the distal-type predominantly revealed the non-large cell type (97\%: 36/37 cases) and rarely disclosed the large cell type (3\%: $1 / 37$ cases) $(P=0.0001)$. The prognosis of the patients with the proximal-type was significantly worse, when compared with that of patients with the distal-type $(P=0.019$; Figure 2$)$. In contrast, no statistically significant difference in prognosis was seen in histological subtype, among the conventional type, the angiomatoid type and the large cell type (Figure 3). The correlation between the clinicopathological parameters in all the epithelioid sarcoma cases and

Table 1 Clinicopathological parameters in 72 cases of epithelioid sarcoma

\begin{tabular}{|c|c|c|c|c|c|c|c|c|c|c|c|}
\hline \multirow{2}{*}{$\begin{array}{r}\text { Site } \\
\text { Proximal }\end{array}$} & \multirow[b]{2}{*}{35} & \multicolumn{2}{|c|}{ Histologic subtype } & \multicolumn{2}{|c|}{ Age (years) } & \multicolumn{2}{|c|}{ Sex } & \multicolumn{2}{|c|}{ Size $(\mathrm{cm})$} & \multicolumn{2}{|l|}{ Depth } \\
\hline & & Conventional & 46 & $\geq 31$ & 32 & Male & 44 & $>5$ & 31 & Deep & 22 \\
\hline Distal & 37 & $\begin{array}{l}\text { Angiomatoid } \\
\text { Large cell }\end{array}$ & $\begin{array}{r}5 \\
21\end{array}$ & $<31$ & 40 & Female & 28 & $\begin{array}{l}\leq 5 \\
\text { Unknown }\end{array}$ & $\begin{array}{r}39 \\
2\end{array}$ & Superficial & 50 \\
\hline \multicolumn{2}{|c|}{ Mitotic rate (per $10 \mathrm{HPFs}$ ) } & \multicolumn{2}{|c|}{ Tumor necrosis (\%) } & \multicolumn{2}{|c|}{ Rhabdoid cells } & \multicolumn{2}{|c|}{ Hemorrhage } & \multicolumn{2}{|c|}{ Vascular permeation } & & \\
\hline$\geq 20$ & 32 & $\geq 50$ & 16 & $(+)$ & 42 & $(+)$ & 46 & $(+)$ & 57 & & \\
\hline \multirow[t]{2}{*}{$<20$} & 40 & $<50$ & 45 & $(-)$ & 30 & $(-)$ & 20 & $(-)$ & 15 & & \\
\hline & & 0 & 11 & & & Unknow & 6 & & & & \\
\hline
\end{tabular}


prognosis is summarized in Table 3 . In univariate analysis, proximal tumor site $(P=0.019)$, male $(P=0.0285)$, large tumor size $(>5 \mathrm{~cm})(P=0.0446)$, deep location $(P=0.0457)$, a high mitotic rate $(\geq 20 /$ 10HPF $)(P=0.0127)$ and massive tumor necrosis $(\geq 50 \%) \quad(P=0.0049)$ were all significantly correlated to a worse overall survival rate.

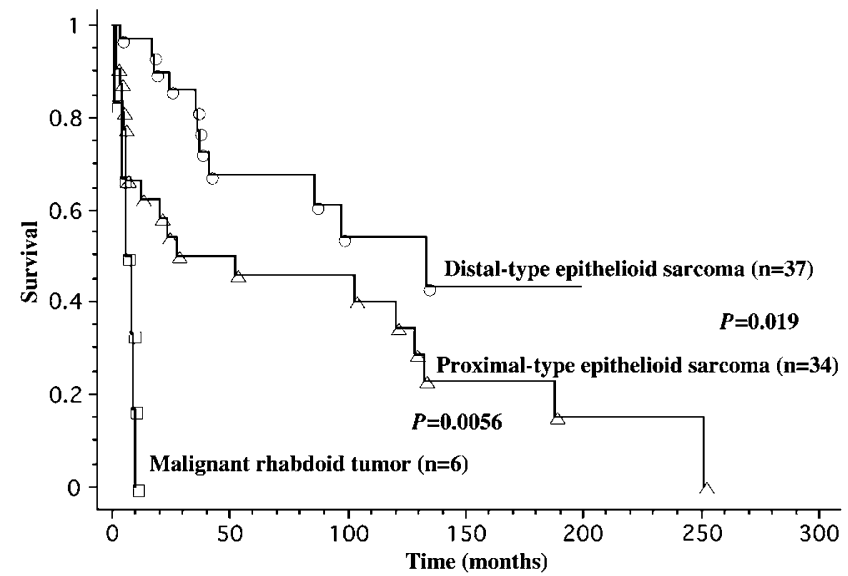

Figure 2 Survival curve of patients with distal-type epithelioid sarcoma, proximal-type epithelioid sarcoma and malignant rhabdoid tumor. The prognosis of patients with proximal-type epithelioid sarcoma was significantly worse than that of patients with distal-type epithelioid sarcoma $(P=0.019)$. Moreover, the prognosis of patients with malignant rhabdoid tumor was significantly worse than that of patients with proximal-type epithelioid sarcoma $(P=0.0056)$.

Table 2 Correlation between tumor site and histologic subtype in epithelioid sarcoma $(n=72)$

\begin{tabular}{lccc}
\hline Histologic subtype & \multicolumn{2}{c}{ Site } & \multirow{2}{*}{ P-value } \\
\cline { 2 - 3 } & Proximal & Distal & \\
\hline Non-large cell & $15(43 \%)$ & $36(97 \%)$ & \multirow{2}{*}{$0.0001^{\mathrm{a}}$} \\
$\quad$ Conventional & $12(34 \%)$ & $34(92 \%)$ & \\
$\quad$ Angiomatoid & $3(9 \%)$ & $2(5 \%)$ & \\
Large cell & $20(57 \%)$ & $1(3 \%)$ & \\
& $35(100 \%)$ & $37(100 \%)$ & \\
& & & \\
\hline
\end{tabular}

${ }^{\mathrm{a} S t a t i s t i c a l l y ~ s i g n i f i c a n t . ~}$

\section{Malignant rhabdoid tumor}

Clinicopathological findings of malignant rhabdoid tumor are summarized in Table 4. There were three cases of extra-renal malignant rhabdoid tumor and three cases of renal malignant rhabdoid tumor. The age of the patients ranged from 0.25 years to 31 years (mean, 6.8 years). All patients died within 10 months. The prognosis of the patients with malig-

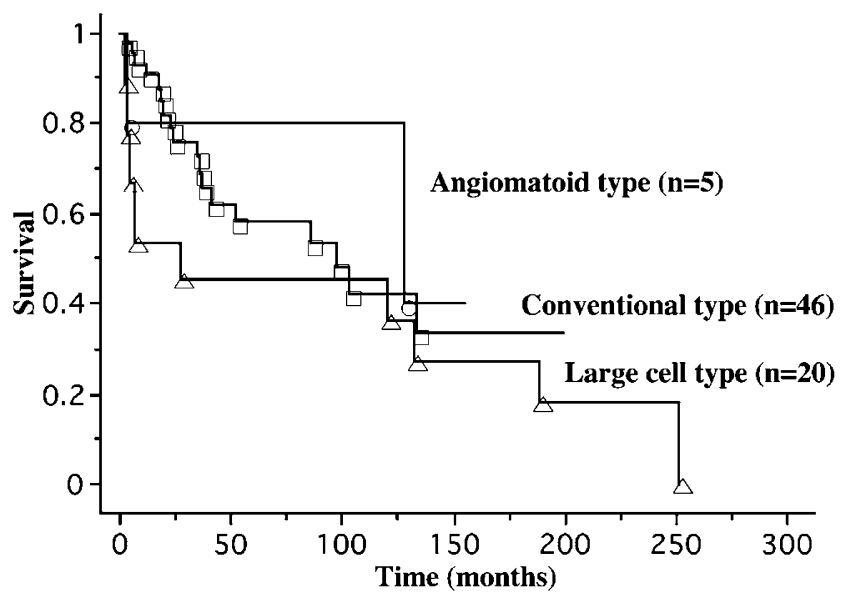

Figure 3 Survival curve of epithelioid sarcoma patients with the angiomatoid type, the conventional type and the large cell type. No statistical significant difference in prognosis was seen among the three histological subtypes.

Table 3 Clinicopathological parameters and prognosis in epithelioid sarcoma $(n=71)$

\begin{tabular}{ll}
\hline Variables & P-value \\
\hline Site (proximal) & $0.0190^{\mathrm{a}}$ \\
Histologic subtype (large cell) & 0.1022 \\
Age $(\geq 31$ years) & 0.0898 \\
Sex (male) & $0.0285^{\mathrm{a}}$ \\
Size ( $>5 \mathrm{~cm}, n=70)$ & $0.0446^{\mathrm{a}}$ \\
Depth (deep) & $0.0457^{\mathrm{a}}$ \\
Mitotic rate $(\geq 20$ per 10 HPFs) & $0.0127^{\mathrm{a}}$ \\
Tumor necrosis $(\geq 50 \%)$ & $0.0049^{\mathrm{a}}$ \\
Rhabdoid cells $(+)$ & 0.6279 \\
Hemorrhage $(+, n=65)$ & 0.4435 \\
Vascular permeation $(+)$ & 0.2123
\end{tabular}

${ }^{\mathrm{a}}$ Statistically significant.

Table 4 Clinicopathological parameters in 6 cases of malignant rhabdoid tumor

\begin{tabular}{|c|c|c|c|c|c|c|c|c|c|}
\hline \multicolumn{2}{|c|}{ Site } & \multicolumn{2}{|c|}{ Age (years) } & \multicolumn{2}{|c|}{ Sex } & \multicolumn{2}{|c|}{ Size $(\mathrm{cm})$} & \multicolumn{2}{|c|}{ Depth } \\
\hline Extra-renal & 3 & $>6$ & 1 & Male & 3 & $>5$ & 3 & Deep & 6 \\
\hline Renal & 3 & $\leq 6$ & 5 & Female & 3 & $\leq 5$ & 3 & Superficial & 0 \\
\hline \multicolumn{2}{|c|}{ Mitotic rate (per $10 \mathrm{HPFs}$ ) } & \multicolumn{2}{|c|}{ Tumor necrosis (\%) } & \multicolumn{2}{|c|}{ Rhabdoid cells } & \multicolumn{2}{|c|}{ Hemorrhage } & \multicolumn{2}{|c|}{ Vascular permeation } \\
\hline$\geq 20$ & 5 & $\geq 50$ & 1 & $(+)$ & 6 & $(+)$ & 6 & $(+)$ & 5 \\
\hline \multirow[t]{2}{*}{$>20$} & 1 & $<50$ & 5 & $(-)$ & 0 & $(-)$ & 0 & $(-)$ & 1 \\
\hline & & 0 & 0 & & & & & & \\
\hline
\end{tabular}


nant rhabdoid tumor was significantly worse, when compared with that of the patients with proximaltype epithelioid sarcoma $(P=0.0056$; Figure 2$)$.

\section{Immunohistochemical Findings in Epithelioid Sarcoma and Malignant Rhabdoid Tumor}

Details of the immunohistochemical findings (dysadherin, E-cadherin and MIB-1) in epithelioid sarcoma and malignant rhabdoid tumor are summarized in Table 5. We could successfully obtain dysadherin-positive staining in the basal cells of normal epidermis, lymphocytes and endothelial cells of epithelioid sarcoma and malignant rhabdoid tumor cases, as an internal positive control. ${ }^{12}$ Dysadherin-positive staining was diffusely and strongly observed in the membranes of epithelioid sarcoma cells in 25/46 cases and it was frequently detected in proximal-type epithelioid sarcoma cases (Figure 4a), whereas dysadherin expression was sometimes absent in distal-type epithelioid sarcoma cases (Figure $4 \mathrm{~b}$ ) but was completely negative in all six malignant rhabdoid tumor cases (Figure 4c). There was a statistically significant difference in dysadherin expression between epithelioid sarcoma and malignant rhabdoid tumor $(P=0.0232$; Table 5). E-cadherin membranous expression was not observed in any of the 46 cases of epithelioid sarcoma or in any of the six cases of malignant rhabdoid tumor. None of the cases showed distinctive membranous staining, but rather showed cytoplasmic or aberrational nuclear staining (Figure $4 \mathrm{~d}$ ). A high MIB-1-labeling index $(\geq 30 \%)^{26}$ was observed in only 29/52 cases (distal-type: 8/23 cases; proximal-type: 21/29 cases) of epithelioid sarcoma, but in five of six cases of malignant rhabdoid tumor. A high MIB-1-labeling index ( $\geq 30 \%)$ was significantly more frequently observed in proximal-type epithelioid sarcoma (Figure 4e) than in distal-type epithelioid sarcoma (Figure $4 \mathrm{f})(P=0.0072)$, whereas no statistically significant difference was seen between the total cases of epithelioid sarcoma and malignant

Table 5 Dysadherin, E-cadherin and MIB-1 immunoreactivity in epithelioid sarcoma and malignant rhabdoid tumor

\begin{tabular}{lccc}
\hline Antibody & $\begin{array}{c}\text { Epithelioid } \\
\text { sarcoma }\end{array}$ & $\begin{array}{c}\text { Malignant } \\
\text { rhabdoid tumor }\end{array}$ & P-value \\
\hline $\begin{array}{c}\text { Dysadherin } \\
(+)\end{array}$ & $(n=46)$ & $(n=6)$ & \\
$(-)$ & 25 & 0 & $0.0232^{\mathrm{a}}$ \\
& 21 & 6 & \\
$\begin{array}{c}\text { E-cadherin } \\
(+)\end{array}$ & $(n=46)$ & $(n=6)$ & \\
$(-)$ & 0 & 0 & \\
& 46 & 6 & \\
MIB-1 (\%) & $(n=52)$ & $(n=6)$ & \\
$\geq 30$ & 29 & 5 & 0.3845 \\
$<30$ & 23 & 1 & \\
\hline
\end{tabular}

${ }^{\mathrm{a}}$ Statistically significant. rhabdoid tumor ( $P=0.3845$; Table 5$)$. The correlations between dysadherin immunoreactivity and clinicopathological parameters in epithelioid sarcoma are summarized in Table 6. Dysadherin expression was significantly more frequently observed in proximal-type epithelioid sarcoma (17/24 cases), than in distal-type epithelioid sarcoma (8/22 cases) $(P=0.037)$. Male patients $(20 / 29$ cases $)$ showed dysadherin expression significantly more frequently than female patients $(5 / 17$ cases $)(P=0.0144)$. Other parameters had no statistically significant correlation with dysadherin expression. Dysadherin immunoreactivity in comparison between malignant rhabdoid tumor and epithelioid sarcoma mimicking malignant rhabdoid tumor are summarized in Table 7. Seven proximal-type epithelioid sarcoma cases and 1 distal-type epithelioid sarcoma case mimicking malignant rhabdoid tumor (histologically classified as the large cell type, accompanied by frequent rhabdoid cells and located in deep soft tissue) were all positive for dysadherin $(100 \%)$, whereas dysadherin expression was not detected at all in any of the true six malignant rhabdoid tumors $(0 \%)$.

\section{Dysadherin mRNA Expression in Epithelioid Sarcoma and Malignant Rhabdoid Tumor}

The two epithelioid sarcoma cell lines, HS-ES-1M and YCUS-5, established from proximal-type epithelioid sarcoma showed higher dysadherin mRNA expression compared to the two distal-type epithelioid sarcoma cell lines, ES-OMC-MN and SFT8606. In contrast, all the four malignant rhabdoid tumor cell lines, TM87-16, TTC549, TC289 and STM91-01 showed no visible dysadherin mRNA expression (Figure 5). Dysadherin mRNA EIs are summarized in Table 8. Only the two proximal-type epithelioid sarcoma cell lines, HS-ES-1M and YCUS-5 showed very high dysadherin mRNA EIs (4387.9 and 472.20 AU; respectively) compared with the hepatoma Li-7 cell line (40.7 AU). As for the comparison between epithelioid sarcoma and malignant rhabdoid tumor, dysadherin mRNA EIs in epithelioid sarcoma (median, 240.34 AU) were significantly higher than those in malignant rhabdoid tumor (median, 0.325 AU) $(P=0.0433)$.

\section{Prognostic Value of Dysadherin Expression in Epithelioid Sarcoma}

Epithelioid sarcoma patients with dysadherin immunoreactivity survived for a significantly shorter time than those without dysadherin immunoreactivity ( $P=0.001$; Figure 6$)$. In addition, distal-type epithelioid sarcoma patients with dysadherinpositive expression had a significantly worse prognosis than those without dysadherin expression $(P=0.0059$; Figure 7a). Proximal-type epithelioid sarcoma patients with dysadherin-positive expression had a tendency to have a poor prognosis 

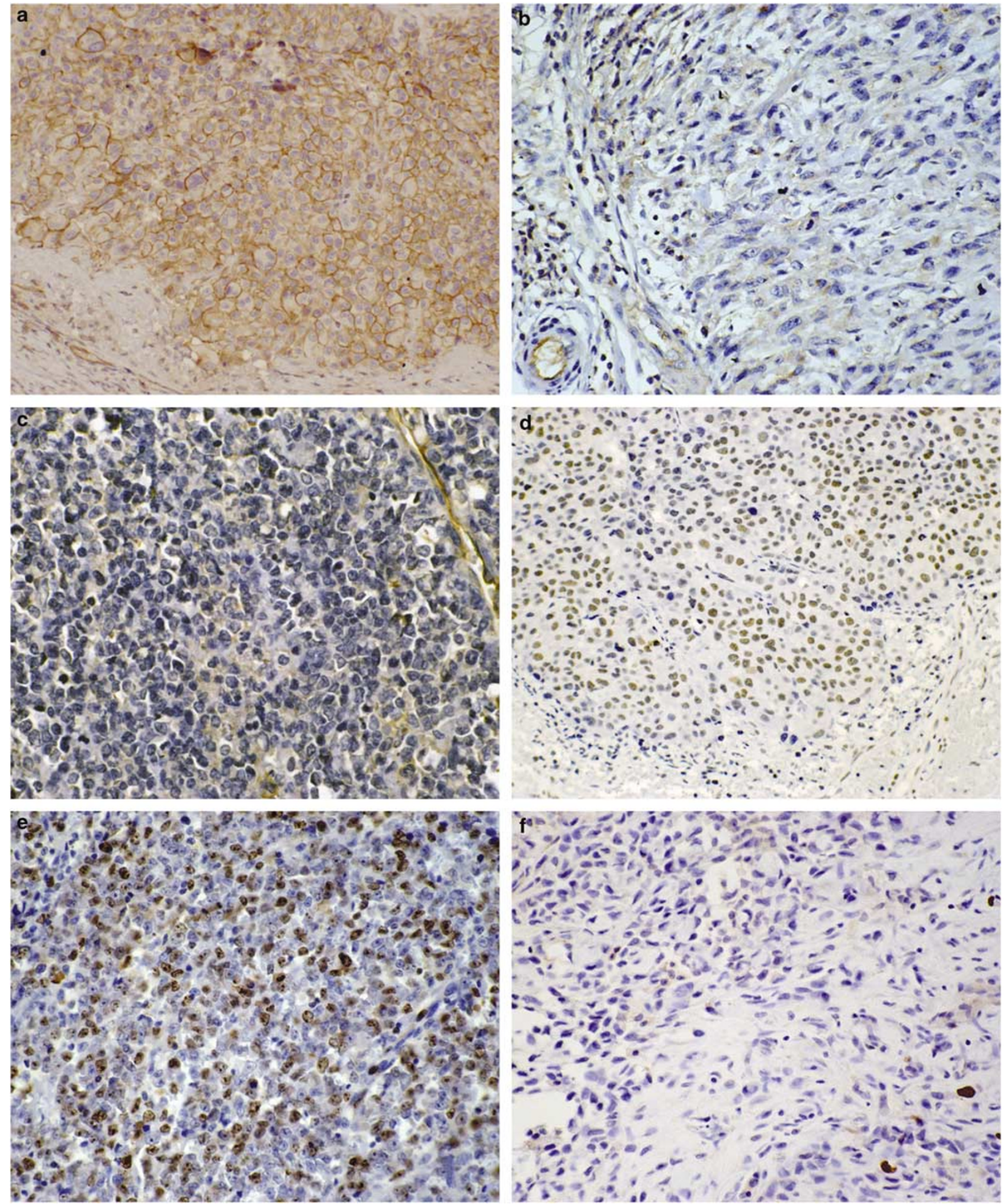

Figure 4 Immunohistochemical staining for dysadherin, E-cadherin and MIB-1. Dysadherin membranous staining was frequently observed in proximal-type epithelioid sarcoma cases (a), whereas dysadherin expression was sometimes absent in distal-type epithelioid sarcoma (b) and was completely negative in all malignant rhabdoid tumor cases (c). Aberrational nuclear staining for E-cadherin was detected in proximal-type epithelioid sarcoma cases (d). A high MIB-1-labeling index ( $\geq 30 \%)$ was frequently seen in proximal-type epithelioid sarcoma cases (e) (MIB-1: 33\%) as compared with distal-type epithelioid sarcoma cases (f) (MIB-1: 4\%). 
compared with those without dysadherin expression $(P=0.1152$; Figure $7 \mathrm{~b})$. Multivariate analysis of the 45 cases for which survival data and immuno-

Table 6 Correlation between dysadherin immunoreactivity and clinicopathological parameters in epithelioid sarcoma $(n=46)$

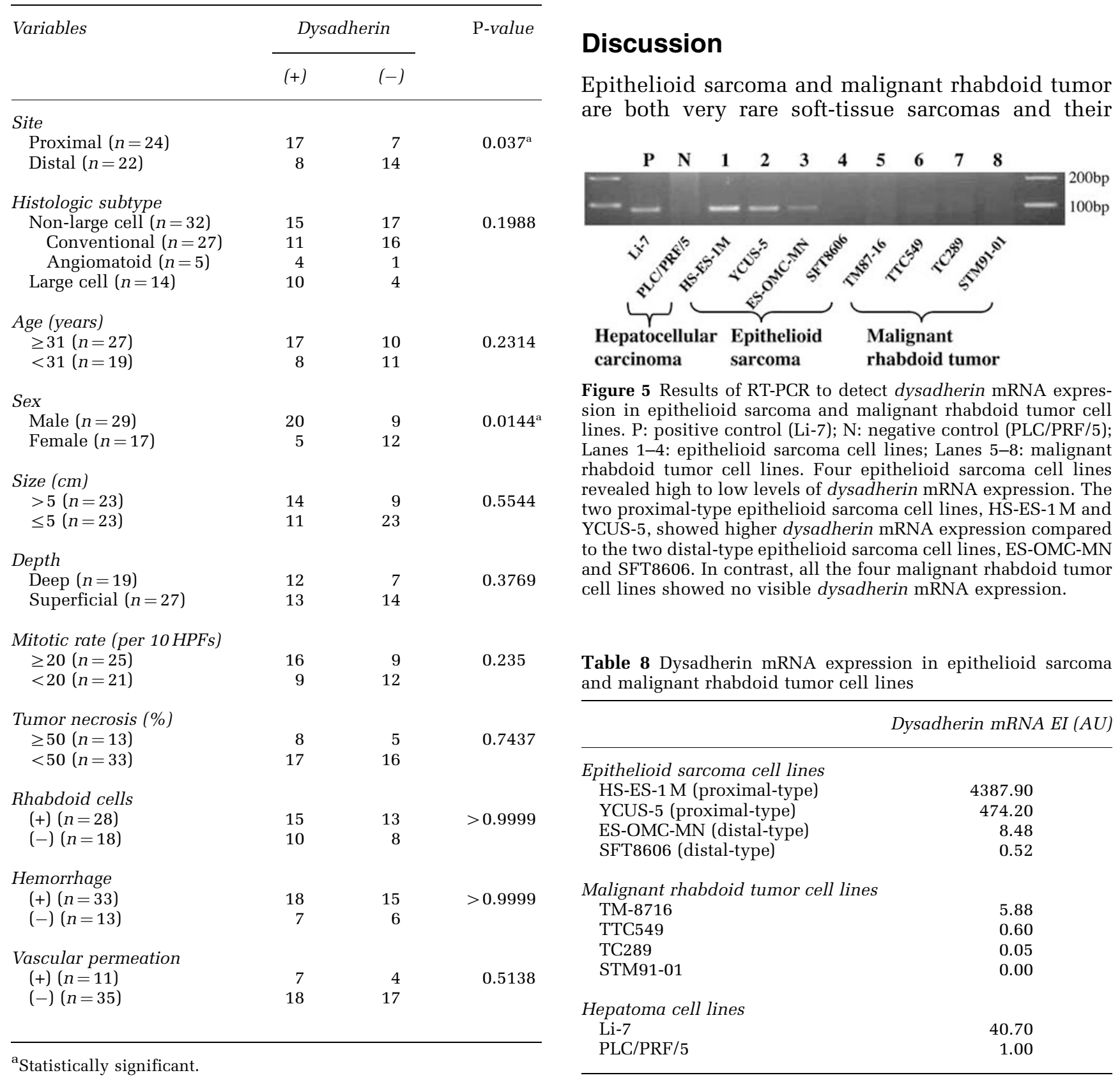

histochemical analysis were available revealed that dysadherin immunopositivity $(P=0.0004)$ and massive tumor necrosis $(\geq 50 \%)(P=0.0006)$ were independent poor prognostic factors (Table 9). Other clinicopathological prognostic factors were not significant.

\section{Discussion}

Epithelioid sarcoma and malignant rhabdoid tumor 


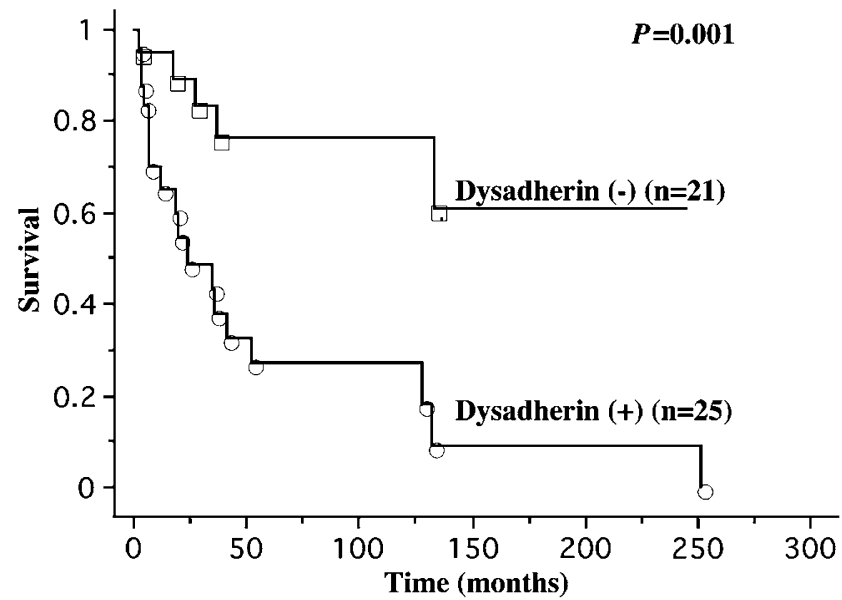

Figure 6 Effect of dysadherin expression on survival in the total cases of epithelioid sarcoma. Epithelioid sarcoma patients with dysadherin immunoreactivity survived for a significantly shorter time than those without dysadherin immunoreactivity $(P=0.001)$.
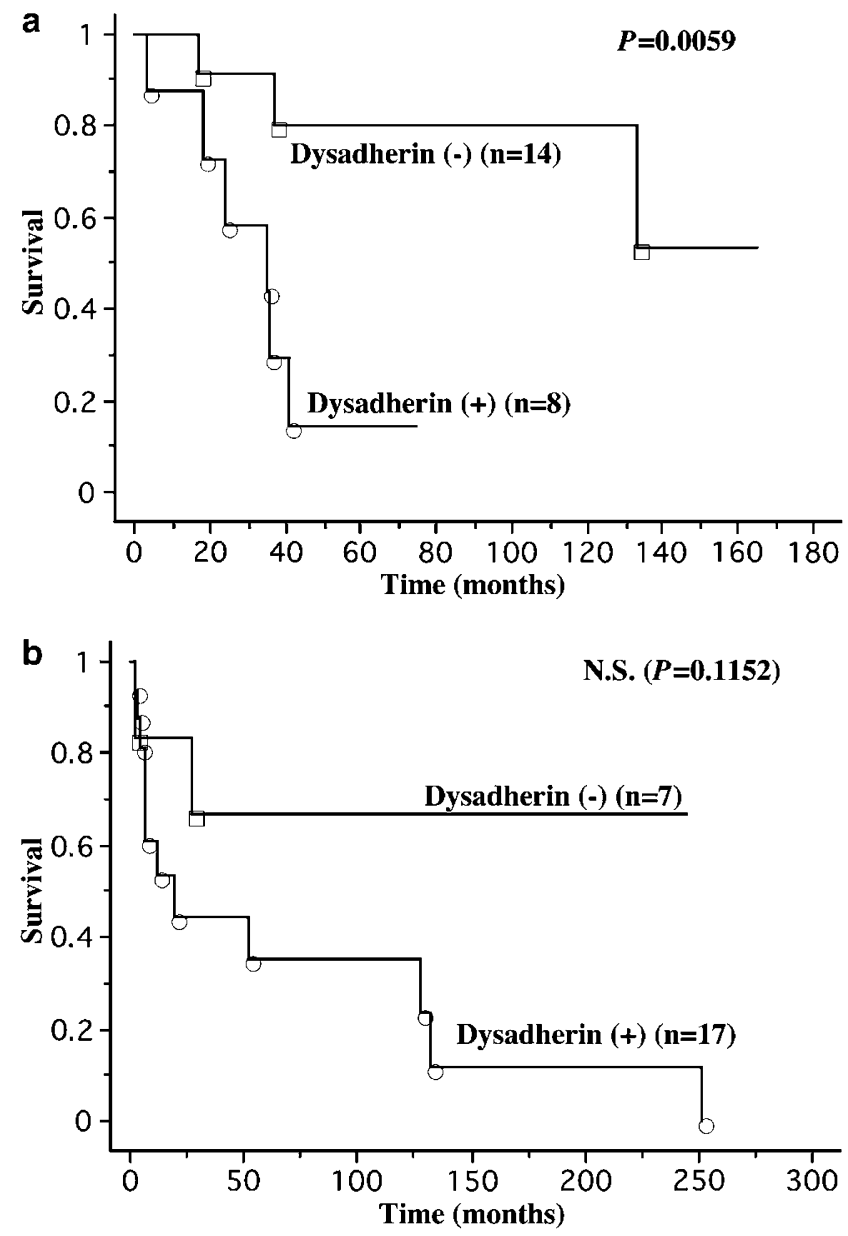

Figure 7 Effect of dysadherin expression on survival in distaltype epithelioid sarcoma and proximal-type epithelioid sarcoma. (a) Distal-type epithelioid sarcoma patients with dysadherinpositive expression had a significantly poor prognosis compared with those without dysadherin expression $(P=0.0059)$. (b) Proximal-type epithelioid sarcoma patients with dysadherinpositive expression had a tendency to have a poor prognosis compared with those without dysadherin expression, although the difference was not statistically significant (NS; $P=0.1152$ ).
Table 9 Survival analysis in epithelioid sarcoma $(n=45)$

\begin{tabular}{llc}
\hline Variables & \multicolumn{2}{c}{ P-value on survival analysis } \\
\cline { 2 - 3 } & Univariate & Multivariate \\
& & \\
\hline Site (proximal) & 0.25720 & 0.67890 \\
Histologic subtype (large cell) & 0.40660 & 0.48110 \\
Age ( $\geq 31$ years) & 0.82870 & 0.93550 \\
Sex (male) & 0.09170 & 0.80950 \\
Size ( $>5 \mathrm{~cm})$ & $0.0362^{\mathrm{a}}$ & 0.53070 \\
Depth (deep) & 0.09800 & 0.68640 \\
Mitotic rate $(\geq 20$ per 10 HPFs) & 0.09080 & 0.27070 \\
Tumor necrosis ( $\geq 50 \%)$ & $0.0047^{\mathrm{a}}$ & $0.0006^{\mathrm{a}}$ \\
Rhabdoid cells (+) & 0.76160 & 0.45570 \\
Hemorrhage $(+)$ & 0.89340 & 0.81070 \\
Vascular permeation $(+)$ & 0.48120 & 0.46180 \\
Dysadherin $(+)$ & $0.0001^{\mathrm{a}}$ & $0.0004^{\mathrm{a}}$ \\
MIB-1 $(\geq 30 \%)$ & $0.0029^{\mathrm{a}}$ & 0.27090 \\
\hline
\end{tabular}

${ }^{\mathrm{a}}$ Statistically significant.

clinicopathological differences, especially when comparing proximal-type epithelioid sarcoma with malignant rhabdoid tumor, are still controversial. In addition, no valuable prognostic markers for epithelioid sarcoma and malignant rhabdoid tumor have been demonstrated in a study of a large series.

Guillou ${ }^{2}$ described that proximal-type epithelioid sarcoma typically demonstrates a diffuse proliferation of large epithelioid cells with marked cytologic atypia (large cell type), whereas Hasegawa ${ }^{8}$ classified 20 cases of proximal-type epithelioid sarcoma into three histologic subtypes (large cell type (60\%), conventional type $(30 \%)$ and angiomatoid type $(10 \%))$. In the current study, both proximal-type epithelioid sarcoma and distal-type epithelioid sarcoma demonstrated three histologic subtypes. In proximal-type epithelioid sarcoma, 20/35 cases (57\%) were classified as the large cell type, 12/35 cases (34\%) as the conventional type, and $3 / 35$ cases $(9 \%)$ as the angiomatoid type. Each percentage of three histologic subtypes was quite similar to that described by Hasegawa. ${ }^{8}$ In distal-type epithelioid sarcoma, 36/37 cases $(97 \%)$ revealed the non-large cell type, but the one case (3\%) disclosed the large cell type. Interestingly, Rakheja ${ }^{27}$ described a case of epithelioid sarcoma that occurred in the hand of a 14-year-old boy and demonstrated the 'large cell type' morphology. In addition, Guillou ${ }^{2}$ presented a case of epithelioid sarcoma in the forearm of 55year-old man with the 'large cell type' morphology (case 18). We considered that the 'large cell type' morphology was not restricted to proximal-type epithelioid sarcoma.

Dysadherin is a cancer-associated cell membrane glycoprotein, which down-regulates E-cadherin and promotes metastasis. ${ }^{12}$ Dysadherin is expressed in a variety of cancer cells and malignant melanoma cells. ${ }^{12-16,28}$ To date, no investigation into dysadherin expression in sarcomas has been reported. 
Both epithelioid sarcoma and malignant rhabdoid tumor are mesenchymal tumors exhibiting epithelial profiles such as immunohistochemical expression of cytokeratin ${ }^{29}$ and epithelial membrane antigen. ${ }^{30}$ They also possess ultrastructural features such as specialized junctions, tonofilaments and microvilli indicative of epithelial differentiation both in vivo ${ }^{31}$ and in tissue culture. ${ }^{32}$ In the current study, we are able to report that immunohistochemical expression of dysadherin is significantly useful for the differential diagnosis between epithelioid sarcoma and malignant rhabdoid tumor, and for the prediction of prognosis in epithelioid sarcoma.

With regard to the differential diagnosis, over $54 \%$ (25/46 cases) of the patients with epithelioid sarcoma showed dysadherin expression. Proximaltype epithelioid sarcoma (71\%; 17/24 cases) showed significantly frequent dysadherin expression, compared with distal-type epithelioid sarcoma (36\%; $8 / 22$ cases). Over the half (15/28 cases) of the epithelioid sarcoma patients with rhabdoid cells showed dysadherin expression. In contrast, dysadherin expression was completely negative in all six malignant rhabdoid tumor cases. Parallel to the immunohistochemical results, proximal-type epithelioid sarcoma cell lines showed significantly higher dysadherin mRNA levels compared to distaltype epithelioid sarcoma or malignant rhabdoid tumor cell lines. It is sometimes difficult to distinguish epithelioid sarcoma, especially proximaltype epithelioid sarcoma, from malignant rhabdoid tumor by histological morphology based on hematoxylin-eosin staining. However, it would seem that immunoreactivity for dysadherin could help to differentiate between distal-type epithelioid sarcoma, proximal-type epithelioid sarcoma and malignant rhabdoid tumor. We have to pay attention to distinguish epithelioid sarcoma from malignant rhabdoid tumor, especially when proximal-type epithelioid sarcoma cases demonstrate the 'large cell type' morphology, accompanied by frequent rhabdoid cells, and located in deep soft tissue. In the current study, seven proximal-type epithelioid sarcoma cases and one distal-type epithelioid sarcoma case mimicking malignant rhabdoid tumor (histologically classified as the large cell type, accompanied by frequent rhabdoid cells and located in deep soft tissue) were all positive for dysadherin (100\%), whereas dysadherin expression was not detected at all in any of the true six malignant rhabdoid tumors $(0 \%)$.

In epithelioid sarcoma, Chase and Enzinger reported that increased patient age, male sex, proximal tumor location, increased tumor size, high mitotic rate, tumor necrosis and hemorrhage, and vascular invasion all had negative prognostic significance. ${ }^{11}$ Evans and Baer reported that the major factor relating to distant metastasis and death from the tumor was the tumor size. ${ }^{33}$ In the present study, proximal tumor site, male, large tumor size $(>5 \mathrm{~cm})$, deep location, a high mitotic rate $(\geq 20 / 10 \mathrm{HPF})$ and massive tumor necrosis ( $\geq 50 \%$ ) were all found to have a significant relationship to poor prognosis in univariate analysis.

Dysadherin evokes tumor aggressiveness by increasing cell motility. ${ }^{12,13,16}$ Dysadherin stimulates cell motility, and contributes directly to the metastatic potential of human pancreatic cancer cells. ${ }^{13,16}$ Previous studies have reported that dysadherin tends to be expressed more frequently in dissociated tumor cells and infiltrative tumor nests than in welldifferentiated tumor nests. ${ }^{13,16}$ In the current study, dysadherin expression was found to be an independent poor prognostic factor by both univariate and multivariate analysis. In the near future, molecular targeting therapy for dysadherin may become one of the first therapeutic choices instead of conventional therapies in cases of epithelioid sarcoma.

Some previous studies have demonstrated a significant correlation between dysadherin expression and E-cadherin expression in tongue carcinoma, ${ }^{16}$ but other studies have failed to demonstrate this correlation in pancreatic, colorectal, or gastric carcinoma. ${ }^{13-15}$ In epithelioid sarcoma and malignant rhabdoid tumor, distinctive membranous expression of E-cadherin was not observed in any cases, and E-cadherin expression was independent from dysadherin expression. Smith et al described the lack of E-cadherin expression in seven cases of epithelioid sarcoma. ${ }^{34}$ Saito et al demonstrated one case of focal membranous and two cases of membranous and cytoplasmic E-cadherin expression among 15 cases of epithelioid sarcoma. ${ }^{35} \mathrm{We}$ reviewed these epithelioid sarcoma cases for the current study, however, and found that they did not demonstrate distinctive E-cadherin membranous expression. We considered and interpreted these cases to be cases of negative E-cadherin membranous expression. Our result was the same as that described by Smith et al, accordingly, we consider that the inactivation of E-cadherin is not caused by dysadherin alone in epithelioid sarcoma and malignant rhabdoid tumor.

With regard to the prognosis of malignant rhabdoid tumor, no dysadherin expression was observed and therefore it could not be a prognostic marker. Malignant rhabdoid tumor is known to have inactivating mutations or deletions of both alleles of the tumor suppressor gene, hSNF5/INI1 on chromosome 22q11.2. ${ }^{36-38}$ We consider that the highly aggressive and lethal biological behavior in malignant rhabdoid tumor is due to abnormalities in this gene. Interestingly, hSNF5/INI1 gene deletions have been reported in proximal-type epithelioid sarcoma, suggesting its involvement in the genesis and/or progression of proximal-type epithelioid sarcoma. ${ }^{39}$ Morphological similarities between malignant rhabdoid tumor and proximal-type epithelioid sarcoma may be partially due to this common genetic disorder.

In conclusion, dysadherin is frequently expressed in epithelioid sarcoma, especially in proximal-type 
epithelioid sarcoma, whereas it is completely absent in malignant rhabdoid tumor. Therefore, the immunohistochemical expression of dysadherin is a significantly useful diagnostic marker for distinguishing proximal-type epithelioid sarcoma from malignant rhabdoid tumor. Moreover, in epithelioid sarcoma, dysadherin expression is an independent adverse prognostic factor, as assessed by multivariate survival analysis.

In epithelioid sarcoma, especially in proximaltype epithelioid sarcoma, increased cell disadhesion and motility by dysadherin plays an important role to acquire aggressive biological behavior. However, in malignant rhabdoid tumor, cell growth cycle that is characterized and regulated by hSNF5/INI1 gene abnormalities seems to be critical to lethal biological behavior rather than dysadherin.

\section{Acknowledgements}

This work was supported in part by Grants-in-Aid for Scientific Research from the Japan Society for the Promotion of Science (15590304, 17659103), Tokyo, Japan. We are grateful to Miss Naomi Tateishi, Miss Yoko Nozuka and Mr Naoto Koyama for their excellent technical assistance. We thank Miss Katherine Miller (Royal English Language Centre, Fukuoka, Japan) for revising the English used in this article.

\section{References}

1 Enzinger FM. Epithelioid sarcoma. A sarcoma simulating a granuloma or a carcinoma. Cancer 1970;26:10291041.

2 Guillou L, Wadden C, Coindre JM, et al. Proximal-type. epithelioid sarcoma, a distinctive aggressive neoplasm showing rhabdoid features. Clinicopathologic, immunohistochemical, and ultrastructural study of a series. Am J Surg Pathol 1997;21:130-146.

3 Perrone T, Swanson PE, Twiggs L, et al. Malignant rhabdoid tumor of the vulva: is distinction from epithelioid sarcoma possible? Am J Surg Pathol 1989; 13:848-858.

4 Ulbright TM, Brokaw SA, Stehman FB, et al. Epithelioid sarcoma of the vulva. Evidence suggesting a more aggressive behavior than extra-genital epithelioid sarcoma. Cancer 1983;52:1462-1469.

5 Tsuneyoshi M, Daimaru Y, Hashimoto $H$, et al. The existence of rhabdoid cells in specified soft tissue sarcomas. Histological, ultrastructural and immunohistochemical evidence. Virchows Arch APathol Anat Histopathol 1987;411:509-514.

6 Molenaar WM, Dejong B, Dam-Meiring A, et al. Epithelioid sarcoma or malignant rhabdoid tumor of soft tissue? Epithelioid immunophenotype and rhabdoid karyotype. Hum Pathol 1989;20:347-351.

7 Enzinger FM, Weiss SW. Malignant soft tissue tumors of uncertain type. In: Enzinger FM, Weiss SW (eds). Soft tissue tumors, 4th edn. Mosby-Year Book Inc: St Louis, 2001, pp 1521-1538.
8 Hasegawa T, Matsuno Y, Shimoda T, et al. Proximaltype epithelioid sarcoma: a clinicopathologic study of 20 cases. Mod Pathol 2001;14:655-663.

9 Guillou L, Kaneko H. Epithelioid sarcoma. In: Fletcher CDM, Unni KK, Mertens F (eds). Pathology and genetics. Tumors of soft tissue and bone. IARC Press: Lyon, 2002, pp 205-207.

10 Miettinen M, Fanburg-Smith JC, Virolainen M, et al. Epithelioid sarcoma: an immunohistochemical analysis of 112 classical and variant cases and a discussion of the differential diagnosis. Hum Pathol 1999;30: 934-942.

11 Chase DR, Enzinger FM. Epithelioid sarcoma. Diagnosis, prognostic indicators, and treatment. Am J Surg Pathol 1985;9:241-263.

12 Ino $\mathrm{Y}$, Gotoh M, Sakamoto M, et al. Dysadherin, a cancer-associated cell membrane glycoprotein, downregulates E-cadherin and promotes metastasis. Proc Natl Acad Sci USA 2002;99:365-370.

13 Shimamura T, Sakamoto M, Ino Y, et al. Dysadherin overexpression in pancreatic ductal adenocarcinoma reflects tumor aggressiveness: relationship to E-cadherin expression. J Clin Oncol 2003;21:659-667.

14 Aoki S, Shimamura T, Shibata T, et al. Prognostic significance of dysadherin expression in advanced colorectal carcinoma. Br J Cancer 2003;88:726-732.

15 Shimada Y, Yamasaki S, Hashimoto Y, et al. Clinical significance of dysadherin expression in gastric cancer patients. Clin Cancer Res 2004;10:2818-2823.

16 Nakanishi Y, Akimoto S, Sato Y, et al. Prognostic significance of dysadherin expression in tongue cancer: immunohistochemical analysis of 91 cases. Appl Immunohistochem Mol Morphol 2004;12: 323-328.

17 Sonobe H, Ohtsuki Y, Sugimoto T, et al. Involvement of 8q, 22q, and monosomy 21 in an epithelioid sarcoma. Cancer Genet Cytogenet 1997;96:178-180.

18 Goto H, Takahashi $\mathrm{H}$, Funabiki $\mathrm{T}$, et al. Brief report. Neural differentiation of a novel cell line, YCUS-5, established from proximal-type epithelioid sarcoma of a child. Med Pediatr Oncol 1999;33: 137-138.

19 Kusakabe H, Sakatani S, Yonebayashi K, et al. Establishment and characterization of an epithelioid sarcoma cell line with an autocrine response to interleukin-6. Arch Dermatol Res 1997;289:224-233.

20 Iwasaki $\mathrm{H}$, Ohjimi Y, Ishiguro $\mathrm{M}$, et al. Epithelioid sarcoma with an 18q aberration. Cancer Genet Cytogenet 1996;91:46-52.

21 Karnes PS, Tran TN, Cui MY, et al. Establishment of a rhabdoid tumor cell line with a specific chromosomal abnormality, 46, XY, t(11; 22)(p15.5ф1.23). Cancer Genet Cytogenet 1991;56:31-38.

22 Narita T, Taga T, Sugita K, et al. The autocrine loop of epidermal growth factor receptor-epidermal growth factor/transforming growth factor-alpha in malignant rhabdoid tumor cell lines: heterogeneity of autocrine mechanism in TTC549. Jpn J Cancer Res 2001;92: 269-278.

23 Kinoshita Y, Tamiya S, Oda Y, et al. Establishment and characterization of malignant rhabdoid tumor of the kidney. Oncol Rep 2001;8:43-48.

24 Ohta S, Crabbe DCG, Tran TN, et al. Malignant rhabdoid tumor. A study with two established cell lines. Cancer 1993;71:2862-2872.

25 Hinoshita E, Uchiumi T, Taguchi K, et al. Increased expression of an ATP-binding cassette superfamily 
transporter, multidrug resistance protein 2, in human colorectal carcinomas. Clin Cancer Res 2000;6: 2401-2407.

26 Hasegawa T, Yamamoto S, Yokoyama R, et al. Prognostic significance of grading and staging systems using MIB-1 score in adult patients with soft tissue sarcoma of the extremities and trunk. Cancer 2002;95: 843-851.

27 Rakheja D, Wilson KS, Meehan J, et al. 'Proximal-type' and classic epithelioid sarcomas represent a clinicopathologic continuum: case report. Pediatr Dev Pathol 2005;8:105-114.

28 Nishizawa A, Nakanishi Y, Yoshimura K, et al. Clinicopathological significance of dysadherin expression in cutaneous malignant melanoma. Cancer 2005; 103:1693-1700.

29 Chase DR, Enzinger FM, Weiss SW, et al. Keratin in epithelioid sarcoma. An immunohistochemical study. Am J Surg Pathol 1984;8:435-441.

30 Daimaru Y, Hashimoto $\mathrm{H}$, Tsuneyoshi $\mathrm{M}$, et al. Epithelial profile of epithelioid sarcoma. An immunohistochemical analysis of eight cases. Cancer 1987;59: 134-141.

31 Fisher C. Epithelioid sarcoma: the spectrum of ultrastructural differentiation in seven immunohistochemically defined cases. Hum Pathol 1988;19: 265-275.
32 Reeves BR, Fisher C, Smith S, et al. Ultrastructural, immunocytochemical, and cytogenetic characterization of a human epithelioid sarcoma cell line (RMHS1). J Natl Cancer Inst 1987;78:7-18.

33 Evans HL, Baer SC. Epithelioid sarcoma: a clinicopathologic and prognostic study of 26 cases. Semin Diagn Pathol 1993;10:286-291.

34 Smith ME, Brown JI, Fisher C. Epithelioid sarcoma: presence of vascular-endothelial cadherin and lack of epithelial cadherin. Histopathology 1998;33:425-431.

35 Saito $\mathrm{T}$, Oda Y, Itakura E, et al. Expression of intercellular adhesion molecules in epithelioid sarcoma and malignant rhabdoid tumor. Pathol Int 2001;51:532-542.

36 Versteege I, Sevenet N, Lange J, et al. Truncating mutations of hSNF5/INI1 in aggressive pediatric cancer. Nature 1998;394:203-206.

37 Biegel JA, Zhou JY, Rorke LB, et al. Germ-line and acquired mutations of INI1 in atypical teratoid and rhabdoid tumors. Cancer Res 1999;59:74-79.

38 Rousseau-Merck MF, Versteege I, Legrand I, et al. hSNF5/INI1 inactivation is mainly associated with homozygous deletions and mitotic recombinations in rhabdoid tumors. Cancer Res 1999;59:3152-3156.

39 Modena P, Lualdi E, Facchinetti F, et al. SMARCB1/ INI1 tumor suppressor gene is frequently inactivated in epithelioid sarcomas. Cancer Res 2005;65:4012-4019. 